among schoolchildren, young adults, and female schoolteachers suggests environmental associations with educational establishments and seasons of the year. Although numbers are small, they also suggest transmission between female subjects and from female to male subjects or vice versa, but not, as a rule, between male subjects.

Temporal clustering observed early in the course of the study might have been due to initial enthusiasm of the referring practitioners, but examination of their referral patterns suggested that this was not the case. A determined search for an infective organism and a transmission mechanism now seems justifiable.

Requests for reprints should be addressed to Dr R Summerly, Department of Dermatology, Central Out-Patients' Department, North Staffordshire Hospital Centre, Stoke-on-Trent, Staffordshire ST4 7PA.

\section{References}

${ }^{1}$ Marshall J. Pityriasis rosea. A review of its clinical aspects and a discussion of its relationship to pityriasis lichenoides et varioliformis acuta and parapsoriasis guttata. $S$ Afr Med $\mathcal{F} 1956 ; 30: 210-8$.

2 Raskin J. Possible dermatropic virus associated with pityriasis rosea. Acta Derm Venereol 1968;48:474-81.
3 Wright AD, Francis RD. Pityriasis rosea. An etiologic study. Arch Dermatol $1961 ; 84: 87-9$.

${ }^{4}$ Silva LG, Gardner PS. Pityriasis rosea-a virological study. Br $\mathcal{F}$ Dermatol $1968 ; 80: 514-5$.

${ }^{5}$ Bjornberg A, Hellgren L. Pityriasis rosea. A statistical, clinical and laboratory investigation of 826 patients and matched healthy controls. Acta Derm Venereol 1962;42,suppl 50.

${ }^{6}$ McPherson A, McPherson K, Ryan TJ. Is pityriasis rosea an infectious disease? Lancet 1980;ii:1077.

${ }^{7}$ Knox EG. Detection of low intensity epidemicity : application to cleft lip and palate. British fournal of Preventive and Social Medicine 1963;17: 121-7.

${ }^{8}$ Knox EG. Epidemiology of childhood leukaemia in Northumberland and Durham. British fournal of Preventive and Social Medicine 1964;18: 17-24.

9 Wallenstein SR, Naus JL. Probabilities for the size of largest clusters and smallest intervals. Fournal of the American Statistical Association 1974; 68:690-7.

${ }^{10}$ Burch PRJ, Rowell NR. Pityriasis rosea-an autoaggressive disease? Br F Dermatol 1970;82:549-60.

11 David FN, Barton DE. Two space-time interaction tests for epidemicity. British fournal of Preventive and Social Medicine 1966;20:44-8.

${ }^{12}$ Mantel $\mathrm{N}$. The detection of disease clustering and a generalised regression approach. Cancer Res 1967;27:209-20.

${ }^{13}$ Pike MC, Smith PG. Disease clustering: a generalization of Knox's approach to the detection of space-time interactions. Biometrics 1968; 24:541-6.

(Accepted 24 November 1981)

\title{
Ultrasound-guided fetal intravenous transfusion for severe rhesus haemolytic disease
}

\author{
JENS BANG, JOHANNES E BOCK, DYRE TROLLE
}

\begin{abstract}
Intrauterine, intraperitoneal transfusion is associated with a poor survival rate in fetuses with hydrops and low gestational age. A method of direct fetal intravenous transfusion was used in two fetuses. One fetus with severe rhesus haemolytic disease was given transfusions in the 29th and 30th weeks of gestation, using an ultrasoundguided needle through the hepatic part of the umbilical vein without fetoscopy. In another fetus, an experimental cannulation of the umbilical vein succeeded in the $23 \mathrm{rd}$ week of gestation.

Ultrasound-guided fetal intravenous transfusion avoids the use of fetoscopy, which has limitations, and may improve the prognosis for rhesus-sensitised fetuses.
\end{abstract}

\section{Introduction}

Intraperitoneal transfusion of unborn infants with severe rhesus haemolytic disease gives poor results when the fetus has hydrops and a low gestational age. ${ }^{1}$ Probably the fetal ascites prevents adequate resorption of erythrocytes, so that in many cases early delivery remains the treatment of choice. ${ }^{2}$

Rodeck et $a l^{3}$ introduced a method of direct intravascular transfusion of fetuses under fetoscopic control at 23 to 26 weeks of gestation. Beyond that age, however, the method could not

Rigshospitalet, 2100 Copenhagen, Denmark

JENS BANG, MD, chief physician, university department of diagnostic ultrasound

JOHANNES E BOCK, MD, chief physician, university department of obstetrics and gynaecology

DYRE TROLLE, MD, professor of obstetrics and gynaecology be used because of problems with the fetoscopic technique. We have therefore tried direct intravenous transfusion of fetuses through the hepatic part of the umbilical vein using a thin needle guided by ultrasound. The procedures conformed with the Declaration of Helsinki 1975.

\section{Materials and methods}

Ultrasound scanning was performed with linear real-time equipment (Aloka). Gestational age was assessed from biparietal diameter and the fetus checked for hydrops and ascites. The intrauterine, intravenous transfusions were carried out under local anaesthesia.

A guide needle $(1.2 \times 150 \mathrm{~mm})$ was introduced into the fetal abdomen 3-4 $\mathrm{mm}$ from the hepatic part of the umbilical vein, and through this a fine needle $(0.6 \times 180 \mathrm{~mm})$ was inserted into the lumen of the umbilical vein. The procedure was visualised by ultrasound, the needle being passed through a special puncture transducer mounted on the scanner. The puncture transducer has a slit in the centre for introducing the needle, which may be fastened or released from the transducer with a wheel at the top. Also the puncture transducer was fitted with a movable scale calibrated in centimetres, by which the route of the needle could be monitored on the oscilloscope. When we scanned with the puncture transducer the scale was pointed directly at the umbilical vein and the tips of the guide needle and fine needle were visualised on the oscilloscope (figure).

Infusing blood into the umbilical vein produced some echoes, and the dispersal of the blood in the fetal vessels was seen on the oscilloscope. The fetal heart rate was measured before and after the transfusion.

\section{Results}

CASE 1

A 33-year-old woman, blood group $\mathrm{O}$, rhesus-negative, was in her fifth pregnancy. The first had ended in spontaneous abortion, but the 
second (1974) had resulted in a normal delivery without rhesus isoimmunisation; she had not been given immunoprophylaxis. The third pregnancy was complicated by anti-D isoimmunisation, but the child was only slightly affected and no exchange transfusions were necessary. The fourth pregnancy was terminated.

The patient was transferred to this hospital from the local obstetric department at 29 weeks after heavily yellow-stained amniotic fluid had been obtained by amniocentesis. Ultrasonic assessment showed a fetus of normal size for 29 weeks. Fetal ascites was present, and the amniotic fluid bilirubin concentration was $14 \mu \mathrm{mol} / 1(0.8 \mathrm{mg} / 100 \mathrm{ml})$, which was in the "severely affected" zone of our prognostic chart. ${ }^{1}$ The

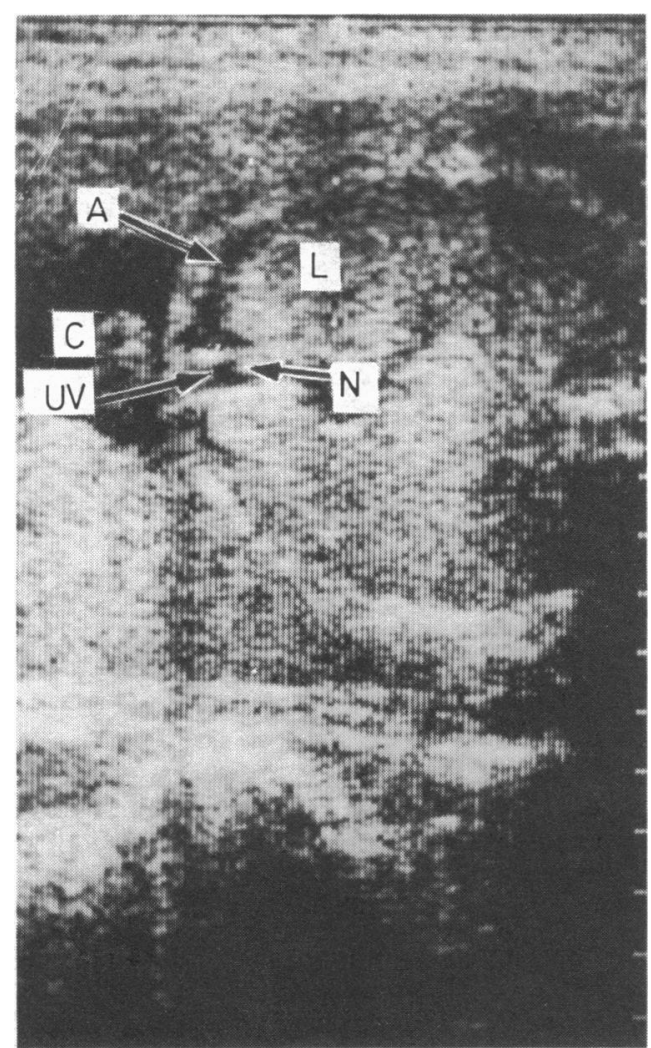

Transverse section of fetal abdomen. $\mathrm{C}=$ Cord. $\mathrm{A}=$ Ascites in fetal abdomen. $\mathrm{UV}=\mathrm{Umbilical}$ vein. $\mathrm{N}=$ Tip of needle in lumen of umbilical vein. $L=$ Liver tissue.

patient was pretreated with betamethazone $12 \mathrm{mg}$ daily for two days, ritodrine $10 \mathrm{mg}$ four times daily, and phenobarbitone $100 \mathrm{mg}$ daily.

We planned an intraperitoneal transfusion with $50 \mathrm{ml}$ group $\mathbf{O}$, rhesus-negative (cde/cde) erythrocytes suspended in sterile isotonic sodium chloride (packed cell volume $0.60(60 \%)$ ). To prevent immunological complications the cell suspension was irradiated with 2160 rads for four minutes before use. During the transfusion we observed a dilated umbilical vein and, with the informed consent of the mother, gave a further $10 \mathrm{ml}$ blood into the hepatic part of the vein. A fetal blood sample, which looked like reddish serum, showed the fetus to be group $A$, rhesus-positive and gave a strongly positive reaction to a direct Coombs test.

A second intravenous transfusion of $25 \mathrm{ml}$ was given one week later. A fetal blood sample before the second transfusion showed a ratio of fetal to adult erythrocytes of $37: 63$.

At 32 weeks a girl of $1700 \mathrm{~g}$ was delivered by caesarean section. The Apgar score was 3 at one minute and 10 at five minutes. The umbilical cord haemoglobin concentration was $6.4 \mathrm{~g} / \mathrm{dl}$ and the bilirubin concentration $144 \mu \mathrm{mol} / 1(8.4 \mathrm{mg} / 100 \mathrm{ml})$. The ratio of fetal to adult erythrocytes was $22: 78$. The infant had a slight bluish discoloration around the umbilicus, possibly a slight haematoma. During the next two days five exchange transfusions were given because of high and rising serum bilirubin concentrations, the highest being $393 \mu \mathrm{mol} / \mathrm{l}$ $(22.9 \mathrm{mg} / 100 \mathrm{ml})$. There were no further complications.
CASE 2

A 25-year-old woman in the 23 rd week of pregnancy was transferred to this hospital for termination after a prenatal diagnosis of genetic $c$ disease (chromosomal abnormality). There was no evidence of rhesus $\widehat{\Omega}$ isoimmunisation. The patient gave permission for an ultrasound- $\overline{\bar{J}}$ guided puncture for fetal blood sampling. Biparietal diameter was

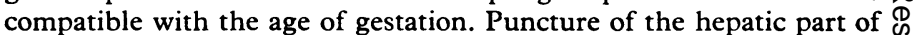
the umbilical vein was performed under epidural anaesthesia. The tip $\Pi$ of the needle was visualised on the oscilloscope in the lumen of the vein and $0.5 \mathrm{ml}$ blood withdrawn. Analysis on a Coulter counter $=$ showed $100 \%$ fetal blood. Subsequently $40 \mathrm{mg}$ dinoprost trometamol $\stackrel{\vec{P}}{\rightarrow}$ (Amoglandin) was instilled into the amniotic cavity for termination.

\section{Comment}

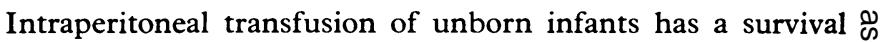
rate of $25-70 \%,,^{1-4}$ depending on the prevalence of fetal hydrops $\vec{\circ}$ and the gestational age when the transfusion is started. Both fetal hydrops and low gestational age appreciably reduce the $\vec{\omega}$ success rate, possibly because of poor resorption of erythrocytes $\Omega$ due to ascites. Despite technical improvements in the transfusion procedure, primarily the use of ultrasound in placing the transfusion needle, rhesus isoimmunisation may be so severe in $\stackrel{\infty}{+}$ some cases that traditional intraperitoneal transfusions are not effective and fetal prognosis is poor. In an earlier study all $14 \stackrel{\omega}{\omega}$ fetuses with amniotic fluid bilirubin concentrations above $10 \omega$ $u \mathrm{~mol} / 1(0.6 \mathrm{mg} / 100 \mathrm{ml})$ died perinatally. ${ }^{1}$

Direct intravascular fetal transfusion might theoretically solve these problems. This treatment could be established at an earlier stage of gestation and might prevent fetal ascites, and thus $T$ remove the problem of peritoneal resorption of erythrocytes. $\frac{10}{0}$ Furthermore, the technique permits precise evaluation of the haematological state of the fetus. Rodeck et $a l^{3}$ described direct intravascular transfusion with the use of fetoscopy. The authors $\vec{\bullet}$ believe that the fetoscopic technique has some limitations: by 26 weeks of gestation the uterus may be too large, the amniotic fluid too cloudy, and the quantity of blood needed for transfusion too great.

In our two patients we succeeded in obtaining fetal blood samples at 23,29 , and 31 weeks of gestation, twice performing a direct intravenous transfusion through the hepatic part of the $\varrho$ umbilical vein.

In severe rhesus isoimmunisation the umbilical venous flow shows a negative correlation with the umbilical cord haemoglobin concentration. ${ }^{5}$ This suggests that the diameter of the umbilical vein increases in fetal anaemia, which, if so, would make cannulation of the umbilical vein possible at later gestational ages and without the elective risk and morbidity from fetoscopy.

Knowledge of various factors-for example, the size of transfusion, the cardiovascular effects of transfusion, the importance of different blood variables in fetal blood-should $\mathrm{O}$ be established, but we hope that direct intravenous fetal transfusion will improve the prognosis of high-risk, rhesus-sensitised $\tilde{\sigma}$ fetuses that cannot be saved by traditional methods.

Requests for reprints should be addressed to JEB, Department of Obstetrics and Gynaecology, Rigshospitalet, Blegdamsvej 9, DK-2100 N Copenhagen $\emptyset$, Denmark.

\section{References}

1 Bock JE. Intrauterine transfusion in severe rhesus hemolytic disease. Acta Obstet Gynecol Scand 1976; suppl 53.

2 Bock JE, Lykkesfeldt G, Trolle D. Early caesarean section in rhesus isoimmunisation. Lancet $1978 ; \mathrm{i}: 210$.

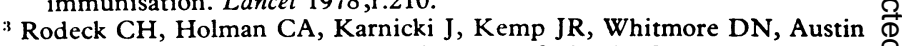
MA. Direct intravascular fetal blood transfusion by fetoscopy in severe rhesus isoimmunisation. Lancet $1981 ; \mathrm{i}: 625-7$.

+ Berkowitz RL, Hobbins JC. Intrauterine transfusion utilising ultrasound. Obstet Gynecol $1981 ; 57: 33-6$.

5 Kirkinen P, Jouppila P, Eik-Nes S. Umbilical venous flow as indicator of fetal anaemia. Lancet $1981 ; \mathrm{i}: 1004-5$.

(Accepted 9 November 1981) 